\title{
Enlightenment of Street Stall Economy on Improving Hands-On Innovation and Entrepreneurship Training for Chinese College Students against the Background of Innovation and Entrepreneurship
}

\author{
Feng Xiao, Juanmei Han*, Sijing He \\ Guangdong University of Foreign Studies, Guangzhou, China \\ Email: ${ }^{\star} 12431906 @ q q . c o m$
}

How to cite this paper: Xiao, F., Han, J. M., \& He, S. J. (2020). Enlightenment of Street Stall Economy on Improving HandsOn Innovation and Entrepreneurship Training for Chinese College Students against the Background of Innovation and Entrepreneurship. Creative Education, 11, 27982805.

https://doi.org/10.4236/ce.2020.1112205

Received: November 25, 2020

Accepted: December 20, 2020

Published: December 23, 2020

Copyright $\odot 2020$ by author(s) and Scientific Research Publishing Inc. This work is licensed under the Creative Commons Attribution International License (CC BY 4.0).

http://creativecommons.org/licenses/by/4.0/

\begin{abstract}
China's modern education system urgently requires entrepreneurship and innovation education. By reading literature, launching questionnaire, and giving interviews, we found that most colleges and universities in China neglect developing students' practical ability in entrepreneurship and innovation education, and that the proposal made in existing research to add practical training just focuses on macro-guidance, with no specific solutions given. Therefore, we innovatively propose to introduce street stall economy into the curriculum based on the features and feasibility of China's street stall economy, and offer recommendations for management and assessment by drawing on the experience of other places in administering street stall economy.
\end{abstract}

\section{Keywords}

Innovation and Entrepreneurship Course, Street Stall Economy, Hands-On Training

\section{Introduction}

In the context of entrepreneurship and innovation, China's CPC Central Committee and State Council attach great importance to innovation and entrepreneurship education in colleges and universities. At the 18th CPC National Congress, it was made clear that it is necessary to increase support for the cultivation of innovative and entrepreneurial talents. In the Opinions of the State Council on Promoting the High-quality Development of Innovation and Entrepreneur- 
ship-to Create an Upgraded Version of "Double Creation" issued in September 2018, it was pointed out as China's economy has shifted from a stage of rapid growth to a stage of high-quality development, there have emerged new and higher requirements for innovation and entrepreneurship education. However, in double creation (namely entrepreneurship and innovation) courses, many colleges and universities merely offer theoretical teaching and ignore training of students' hands-on abilities.

To promote the development of students' practical innovative and entrepreneurial abilities, improve the quality of college education, and meet China's demand for practice-oriented talents, we proposed to incorporate street stall economy into hands-on innovation and entrepreneurship training based on the requirements of double creation courses and the characteristics of China's street stall economy, and offered suggestions on specific implementation and evaluation mechanisms.

\section{Research Background}

\subsection{The Importance of Innovation and Entrepreneurship Courses for College Students}

President Xi Jinping clearly stated that innovation and entrepreneurship education should be implemented throughout the process of talent training, thereby cultivating creative talents with creative education, and building China into an innovative country with creative talents. Gao Xia suggested that to realize the transformation from a large manufacturing country to a world creation power, China must carry out "mass entrepreneurship and innovation", a feat of the era. College students are the future of a country, so China should attach importance to cultivating their innovation and entrepreneurship capabilities and train them into pioneers of innovation and entrepreneurship (Gao, 2020). Fu Chunquan further pointed out that improving innovation and entrepreneurship education system for college students is the key to enhancing their innovation and entrepreneurship capabilities. Only by quickly promoting an integrated, three-dimensional, and full participation innovation and entrepreneurship education system can colleges and universities cultivate more talents with innovation consciousness, entrepreneurial thinking and creation abilities (Fu, 2020).

\subsection{Problems with Current Innovation and Entrepreneurship Courses}

Many colleges and universities offer double creation courses following China's relevant policies and regulations, but they emphasize theory and neglect practice in actual teaching. As a result, the courses fail to improve students' hands-on innovation and entrepreneurship abilities. Chen Yongzhong et al. launched questionnaire and interviews with students from 9 colleges and universities in Jiang$\mathrm{xi}$, and found that innovation and entrepreneurship education offered by them included no hands-on training, and that students expect to attend project-based 
training (Chen \& Lu, 2020). Gao Xia pointed out that while delivering courses, many schools just focus on the form of education but ignore timeliness and effectiveness, thus resulting in "formalism". Therefore, it is necessary to conduct reform and innovation to solve such problems, and explore new models of education (Gao, 2020).

\subsection{Measures for Improving Hands-0n Training in Innovation and Entrepreneurship Courses}

In response to lack of practical training, some researchers put forward different suggestions. Guo Junqing et al. believe that "Internet+" should be integrated into double creation education, in which teachers guide students to understand "Internet+" entrepreneurial model under the new normal, and cultivate their sense of innovation and entrepreneurship (Guo \& Mao, 2020). Portfolio thinking such as "Internet+" applet, "Internet+" agricultural products, and "Internet+ medical service" can be used to enrich innovative and entrepreneurial thinking and provide strong support for practice. Fu Chunquan suggested that entrepreneurial incubation base for college students should be put into full play, and that the government and institutions of higher learning should increase financial and technical support for promising entrepreneurial projects (Fu, 2020). Guo Xiaoqing et al. pointed out that street stalls feature low investment, easy operation, low risks, early results, and feasible venue offered by schools, being a kind of entrepreneurial activity with strong positive entrepreneurial atmosphere and having attracted more and more attention (Guo, Li, Guan, \& Jiang, 2020).

In summary, innovation and entrepreneurship courses for college students are of great significance in alleviating social employment pressure and improving students' innovation and entrepreneurship capabilities. However, lack of hands-on training is a major problem that needs to be resolved. As for solutions, many scholars have made their points from the perspective of Internet + , funds from the government and universities, or incubation platform, while less attention is paid to offline models with quick returns and low cost. Besides, in studies where street stall model is introduced, researchers just provide a macro direction, and fail not elaborate on how to implement the model in the curriculum or propose management and assessment mechanisms.

\section{Analysis on Present Situation of Innovation and Entrepreneurship Courses for College Students in China}

\subsection{Present Situation of Innovation and Entrepreneurship Courses}

In a survey of "knowledge and ability you expect to gain in innovation and entrepreneurship education", college students generally dislike instilling of theoretical knowledge, but show solicitude for selecting innovation and entrepreneurship projects, conducting innovation and entrepreneurship, and acquiring practical knowledge including operation and management. 
Guangdong is the largest province in China, which enjoys a relatively high degree of popularization of innovation and entrepreneurship education. Colleges and universities there are representative examples for research on innovation and innovation courses. We launched questionnaire in 7 key universities there, the results of which show that students surveyed didn't receive any hands-on training, but just attended theoretical teaching and accepted competition guidance. In the multiple-choice question on existing problems with innovation and entrepreneurship courses, nearly $70 \%$ of students chose lack of platform and opportunity for entrepreneurial practice.

\subsection{Statement of Problem}

Materials and data we collected reflect a problem that urgently needs to be solved in innovation and entrepreneurship courses for college students-lack of handson training. Mere classroom teaching leads to failure to fulfill the original purpose of offering such courses. Cultivating students' innovation and entrepreneurship awareness has become empty talk. Besides, those less interesting and practical courses also reveal that college graduates in China have a weak sense of entrepreneurship, whose self-employment rate stand at only $2.86 \%$, which is far lower than $20 \%$ to $30 \%$ in developed countries. What's more, their entrepreneurial success rate is only about $2 \%$ (Zhang \& Ma, 2016). To truly exert the effects of innovation and entrepreneurship courses, it is imperative to improve hands-on training in the curriculum.

\section{Analysis of Street Stall Economy}

\subsection{Development of Street Stall Economy}

Street stall economy refers to an economic form of obtaining income through street vending. In the process of urbanization in China, it was once considered to be a marginal urban economy and a key factor affecting the appearance and environment of a city. However, due to its unique advantages, it can relieve the huge pressure on social employment to a certain extent under financial crisis.

When inspecting Yantai in Shandong Province in June 2020, Premier Li Keqiang of China's State Council pointed out that street stall economy and small shop economy are important sources of jobs, worldly economic models, and China's vitality just like "high-end" economic models. During the Two Sessions in the same year, Premier Li Keqiang once again recognized street stall economy. For thousands of years, street stall economy has existed in China's rural markets and cities and played a positive role in people's livelihood, economy, and urban culture. During the COVID-19 pandemic, its outstanding performance in relieving employment pressure and boosting the economy has attracted more and more people.

\subsection{Feasibility of Introducing Street Stall Economy}

The following characteristics of "street stall economy" enable it to be well inte- 
grated into innovation and entrepreneurship courses for college students.

1) Low threshold. No high skills or professional threshold is required. All students attending such courses can participate in it, which is beneficial to the full coverage of hands-on training of the courses.

2) Low investment and low risk. Relatively low investment makes it a low-cost but effective method for some not sufficiently funded universities to improve hands-on training. In addition, street vending is an entrepreneurial platform with high fault tolerance and low trial and error costs for college students. In case the ends do not meet or a loss is predicted, students may stop the loss in time and change the business content.

3) High flexibility. Students can start business by putting up a table and chair or spreading a carpet, without the need for laborious construction, while universities just need to leave an open space for them and make rules, which is simple and effective.

4) Strong sense of practical experience. Street vending requires students' communication skills, marketing capabilities, and adaptability. Different from making market demand assumptions and market environment speculations in business plan, it is a real market environment for college students where they can implement their ideas, truly explore consumers' views on products they sell, and enhance their practical ability.

5) Visualized result and effective assessment. Analysis of turnover and stall influence over a period of time helps universities improve course assessment system and evaluate students more objectively and impartially (Wang, 2020).

\section{Ways to Introduce Street Stall Economy into Innovation and Entrepreneurship Courses}

Data collected from questionnaires reveal that current innovation and entrepreneurship courses want for hands-on training on college students, and that students express the need for practical opportunities and platforms. Based on analysis of the characteristics and feasibility of street stall economy, we have proposed four innovative ways to introduce it into the curriculum and formulated targeted management and assessment mechanisms, aiming to use a low-cost but effective way to deal with lack of practical training. Enhance students' innovation and entrepreneurship abilities to a greater extent, and bring more actual benefits out of those courses.

\subsection{Four Approaches of Innovation}

1) Launch street stall economy month or "monthly market". Universities may mark out a hands-on training space on the campus. By dividing stalls for each school and class and assigning duties to each person, universities can ensure good order and clean environment. Students can apply theoretical knowledge they have learned in class or turn their entrepreneurial ideas into reality in prescribed venue. Such activities can not only increase students' interest and con- 
sciousness in receiving innovation and entrepreneurship education, but also provide them with a platform to implement theories and ideas, and effectively enhance their innovation and entrepreneurship capabilities.

2) Set up college student fair in places where universities gather. Taking Guangzhou Higher Education Mega Center as an example. A relatively fixed space may be marked out in the stadium in its center or an open area in a university for students. In this fair, customers are more diversified instead of mere teachers and students, which can enhance students' entrepreneurial resilience and practical ability to a greater extent. In addition, such hands-on training platforms for college students can promote mutual exchanges among students from different universities, enabling them to learn from each other and share entrepreneurial ideas and experiences.

3) Hold entrepreneurship competition. Entrepreneurship contests may be held within universities, between universities and well-known enterprises or among universities to create an atmosphere of innovation and entrepreneurship, and promote students to combine relevant theories with practice. Existing innovation and entrepreneurship competitions have their shortcomings. For example, course contest for China College Students' "Internet Plus" Innovation and Entrepreneurship Competition focuses only on evaluating proposals. "BAB" competition just choose teams with outstanding proposals for follow-up training, which means a small portion of students can put into practice their entrepreneurial ideas. In contrast, entrepreneurship competitions mentioned herein lay stress on actual results of entrepreneurship and offer "Best Creativity Award", "Best Popularity Award", "Best Sales Award" and "Excellent Team Award" to commend participating teams (Hu, 2020).

4) Support cloud stalls. The rapid development of the Internet and 5G technology has brought about new sales models and greatly affected people's consumption habits. Street stall economy can be integrated into entrepreneurship courses by the Internet. Students can start online stores and carry out diversified marketing. In this way, they not only adapt to current trends of social consumption, but also base themselves on new sales models to implement entrepreneurial ideas and combine offline and online training. In recent years, as live commerce show vigorous growth, officials in rural areas also sell unsalable goods through it to help farmers. By combining street stall economy with the Internet, students will embrace a greater platform for practice and better put into practice their innovative ideas. We saw some innovative marketing strategies in street stall economy on some well-known short video platforms. Typical cases include "Meng Po" stall on Wanda Gold Street, Zhengzhou, which is surrounded by customers, and particularly popular Song Dynasty nut cake stall because of interesting and diverse peddling, which quickly attracted the attention of many netizens. Therefore, introducing street stall economy into the classroom and extending it through "Internet plus" can break through the limitations of space and provide college students with a larger platform. 


\subsection{Management and Assessment Mechanisms}

Establishing and improving corresponding management and assessment mechanisms is conducive to improving students' enthusiasm for attending courses and regulating teaching order. In response to the four ways mentioned above, we make the following suggestions:

1) Score students' innovation and entrepreneurship idea, proposal, and implementation plan for the early stage to examine their theoretical knowledge and dialectical thinking. This part accounts for $20 \%$ of the total score.

2) Grade students' practical operations from the following perspectives. This part accounts for $80 \%$.

i) Among campus stall day, college student fair, and cloud stall, it is advised to launch campus stall day first for trial and error. Students may adjust their marketing strategy or theme after this stage and start online shops optionally. After campus stall day is over, teachers will review the marketing of each team and put forward suggestions, so that students can make adjustments accordingly and perform better in college student fair. In the former two activities, teachers may score students' marketing income, marketing creativity, popularity, etc., which accounts for $60 \%$ of total score. Those who launch online marketing can get extra points on this basis.

ii) In entrepreneurship competition, teams will be assessed comprehensively including proposal and result. "Best Creativity Award", "Best Popularity Award", "Best Sales Award" and "Excellent Team Award" will be given. Outstanding teams can get extra points. This part accounts for $20 \%$ of total score.

\section{Conclusion}

The actual effect of innovation and entrepreneurship courses for college students is of great significance to developing China's innovation and entrepreneurship and cultivating college students' innovation and entrepreneurship abilities. Currently, colleges and universities in China offering innovation and entrepreneurship education emphasize fulfilling the requirements of education departments and following mainstream curriculum trends, but lack in-depth understanding and research on relevant courses, which result in relatively casual curriculum and inadequate attention to hands-on training. The agility and practical experience of street stall economy can make up for shortcomings of such courses in hands-on training. Different from heavily funded incubation bases, street stall economy proposed by us can be realized only with vacant spaces. Unlike entrepreneurship platforms with strict screening conditions and a limited number of participants, the low threshold of street stall economy can provide all students with the opportunity to carry out entrepreneurship. The unique value of this proposal is that it can solve current lack of practical training in a low-cost but rapid and effective manner, be adopted by every college and university without being interrupted by insufficient funding or other reasons. We hope to combine theory and practice in this way, truly stimulate students' sense of innovation, 
and develop their entrepreneurial abilities.

On the other hand, there are shortcomings in this study. For example, our questionnaire was sent in a small quantity in a limited scope, and covered just a few majors. To further promote the implementation of our proposal, the scope of the survey should be expanded to obtain more accurate and objective data, and another questionnaire on the four approaches of innovation, management and assessment mechanisms should be sent to college students and teachers. On this basis, researchers analyze feedback and opinions of respondents, improve the proposal, and perfect the approaches and mechanisms.

\section{Funding}

This study belongs to 2020 Guangdong Province project of innovation ability training for college students, titled On Rural Live-stream E-commerce in the Context of Poverty Alleviation-From the Perspective of Supply Chain, and umbered S202011846033.

\section{Conflicts of Interest}

The authors declare no conflicts of interest regarding the publication of this paper.

\section{References}

Chen, Y. Z., \& Lu, J. F. (2020). Research on the Status Quo of Innovation and Entrepreneurship Education for College Students-Taking 9 Universities in Jiangxi Province for Example. Journal of Yuzhang Normal University, 35, 51-54.

$\mathrm{Fu}, \mathrm{C}$. Q. (2020). Problems in Innovation and Entrepreneurship Education for College Students and Countermeasures. Continue Education Research, 6, 78-81.

Gao, X. (2020). Exploration of a New Model of Innovation and Entrepreneurship Education for College Students under the Background of "Double Creation" Education. Chi na Market, 32, 175-176.

Guo, J. Q., \& Mao, W. (2020). Analysis of Strategies for Integrating “Internet +" into Innovation and Entrepreneurship Education for College Students. Industrial Innovation, 19, 136-137.

Guo, X. Q., Li, C. Y., Guan, M. W., \& Jiang, B. F. (2013). Thoughts on the Causes and Solutions for Street Stall Economy in University Clusters. China Business \& Trade, 23, $186-188+192$

$\mathrm{Hu}, \mathrm{H}$. (2020). Exploration and Analysis of the Cultivation of College Students' Core Competence in Innovation and Entrepreneurship. Science and Technology \& Innovation, 18 , 80-81.

Wang, Y. G. (2020). Research on the Innovation and Entrepreneurship Model of Finance and Economics Undergraduates from the Perspective of Internal and External DrivesTake Street Stall Economy as an Example. Quality and Market, 11, 40-42.

Zhang, X. E, \& Ma, T. N. (2016). Practice and Enlightenment of Promoting College Students' Innovation and Entrepreneurship in Foreign Countries. Economic Review, 10, 98-101. 